\title{
The moderating effect of employment status on the relationship between lifetime major depressive disorder and positive mental health
}

\author{
Rajeswari Sambasivam ${ }_{B S c}$, Janhavi Ajit Vaingankar ${ }^{1} M S c$, Edimansyah Abdin ${ }^{1}{ }_{P h D}$, Fiona Devi ${ }^{1}{ }_{B A}$, \\ Boon Yiang Chua ${ }^{1}$ Msc, Saleha Shafie ${ }^{1}{ }_{B S o o s c i}$, Sherilyn Chang ${ }^{1}$ BSocsci, Shazana Shahwan ${ }^{1}$ MClinPsych, \\ Siow Ann Chong ${ }^{1}$ MMed (Psychiatry), Mythily Subramaniam ${ }^{1}$ PhD
}

\begin{abstract}
Introduction: This paper aims to examine the (1) level of positive mental health (PMH), (2) identify the socio-demographic correlates of the PMH domains in the general population, and (3) establish if employment status moderates the relationship between major depressive disorder (MDD) and PMH among those with a lifetime prevalence of MDD.

Methods: The Singapore Mental Health Study conducted between 2016 and 2018 included Singapore residents aged $\geq 18$ years. The World Health Organization Composite International Diagnostic Interview version 3.0 was utilised to establish lifetime prevalence of MDD. Moderation analysis was conducted using SPSS PROCESS macro (Hayes, 2017) to assess if employment status moderated the relationship between MDD and PMH.

Results: Significantly lower PMH total and domain scores were reported by respondents $(n=2,270)$ who endorsed lifetime MDD compared to those who did not. Moderation analysis demonstrated that the effect of MDD on PMH total and domain scores varied considerably across employment status. Based on the interaction plots, the effect of MDD on both PMH total and domain scores was minimal among those employed than unemployed.

Conclusion: Healthcare professionals should support the employment needs of those who report lifetime MDD to provide care for an individual's mental well-being in a holistic manner. Acquiring or remaining in employment would be a priority depending on the $\mathrm{PMH}$ of the individual. Reducing barriers to employment for those with health issues or creating employment opportunities for this group are concerns that need to be addressed at a societal level.
\end{abstract}

Ann Acad Med Singap 2022;51:74-86

Keywords: Depression, employment, positive mental health, well-being

\section{INTRODUCTION}

Studies across the world have reported a high prevalence of mental disorders, ${ }^{1-3}$ highlighting that mental disorders remain one of the major causes of "non-fatal burden". ${ }^{4}$ In particular, major depressive disorder (MDD) has been identified as a highly prevailing mental disorder and the leading cause of disability worldwide. More than 300 million people suffer from MDD globally, making mental illness a major contributor to the overall global burden of disease. ${ }^{5}$

Mental health is a state of physical, mental and social well-being, whereby the individual is capable of leading an economically and socially productive life. ${ }^{5}$ Keyes $^{6}$ proposed a two continua model, which holds that positive mental health (PMH) and mental illness are related but distinct dimensions: one continuum indicates the presence or absence of mental health, while the other indicates the presence or absence of mental illnesses. ${ }^{7}$ This model depicts 4 probable conditions that an individual might experience: flourishing with or without mental illness, languishing with or without mental illness. ${ }^{8}$ Therefore, this puts forth the notion that individuals with mental disorders are able to experience high life satisfaction and functioning. Huppert ${ }^{9}$ discussed that PMH incorporates a combination of subjective well-being and of being "fully functional". This is in parallel to Keyes' terminology, in that PMH encompasses positive emotions and functioning. This definition more

\footnotetext{
${ }^{1}$ Research Division, Institute of Mental Health, Singapore

Correspondence: Ms Rajeswari Sambasivam, Research Division, Institute of Mental Health, 10 Buangkok View, Singapore 539747.

Email: Rajeswari_sambasivam@imh.com.sg
} 


\section{CLINICAL IMPACT}

\section{What is New}

- This study highlights the need to simultaneously focus on the vocation goals of people with lifetime depression while addressing their mental well-being needs.

- Findings emphasise that a holistic approach is vital for well-being, and integration of healthcare services should continue.

\section{Clinical Implications}

- The study supports the need to adopt a client-centred approach to care for a person's well-being in a holistic manner.

- The findings can direct healthcare professionals to concurrently address employment and mental health needs of individuals.

notably brings together 2 distinct approaches to defining well-being: the hedonic perspective that highlights feelings of pleasure attainment or happiness, and the eudaimonic perspective that emphasises psychological well-being with the focus on fulfilment, meaning in life and purposefulness. ${ }^{10,11}$ Research has consistently shown that individuals who maintain high levels of $\mathrm{PMH}$ are more likely to recover from an affective disorder than those with low PMH. ${ }^{12}$

Mental well-being is influenced by a number of sociodemographic factors such as age, sex, marital status, education, income, religion and physical health, among others. ${ }^{13}$ Most epidemiological studies worldwide generally indicate a close link between psychiatric symptomatology and socio-economic determinants, with the most vulnerable being individuals of low socio-economic status. ${ }^{14}$ Mental well-being and employment status have a bidirectional yet complicated relationship. ${ }^{15}$ Those who are mentally ill have higher unemployment rates or diminished work productivity. ${ }^{16}$ The effect of being employed may create a positive impact on one's well-being by providing a sense of personal identity and financial security. However, it may also encourage pressure due to the increasing demands of work life, which in turn causes distress to the physical and mental well-being of an individual. ${ }^{17}$ Evidence suggests a strong association between unemployment and a number of adverse health outcomes such as the incidence (and deterioration) of physical and mental well-being. ${ }^{18,19}$ A meta-analysis of 237 cross-sectional and 87 longitudinal studies found those unemployed reported more distress than employed persons. The study also discussed the correlation between the lack of employment and poor mental health. ${ }^{20}$

Singapore is a Southeast Asian country comprising a multiethnic population of 5.6 million including $74.3 \%$ Chinese, $13.4 \%$ Malay, 9\% Indians and 3.2\% other ethnic groups. ${ }^{21}$ The overall unemployment rate in Singapore was reportedly $2.3 \%$ in $2019 .{ }^{22}$ The first Singapore Mental Health Study conducted in 2010 (SMHS 2010) was the first comprehensive mental health survey of a representative sample of its adult resident population, and the lifetime prevalence of MDD was found to be $5.8 \% .^{23}$ The second Singapore Mental Health Study carried out in 2016 (SMHS 2016) was initiated to obtain up-to-date information regarding the prevalence of select mental disorders, and the lifetime prevalence of MDD was reported as $6.3 \% .^{24}$ The positive mental health instrument (PMHI) was developed as part of the SMHS 2010 study. ${ }^{25}$ Several studies on PMH have been conducted in Singapore and provided information on the socio-demographic correlates in various populations, specifically the general community ${ }^{26,27}$ and in people seeking treatment for mental illness. ${ }^{28,29}$ Few studies, however, have looked at the moderating effect of employment status on the relationship between $\mathrm{PMH}$ and MDD. MDD is the most prevalent lifetime mental disorder in Singapore, ${ }^{24}$ and comes with a significant cost to society. Mean annual total costs per patient with depressive disorder has been reported to be USD7,638, with indirect costs at $81 \%$ making up most of the total costs. Almost $50 \%$ of indirect costs were observed to be associated with unemployment and loss of productivity. ${ }^{30}$ Moreover, with reports acknowledging that $\mathrm{PMH}$ is impacted in people with $\mathrm{MDD}^{26,29}$ this study aimed to (1) examine the level of $\mathrm{PMH}$, (2) identify the socio-demographic correlates of the $\mathrm{PMH}$ domains in the general population, and (3) ascertain if employment status moderates the relationship between MDD and $\mathrm{PMH}$, among those with lifetime MDD.

\section{METHODS}

\section{Survey population}

The SMHS 2016 was a population-based, epidemiological study that included Singapore residents aged $\geq 18$ years, conducted between 2016 and 2018. The study was approved by the National Healthcare Group Domain Specific Review Board. Participants were randomly selected from a national registry of citizens and permanent residents in Singapore using a disproportionate stratified sampling design due to the multiethnic nature of the Singapore population. Residents aged $\geq 65$, Malays and Indians were over- 
sampled to ensure that sufficient samples sizes were achieved to improve the reliability of estimates for these groups. The dataset was later adjusted by survey weights that incorporated sampling weight, nonresponse weight and post-stratification weight by ethnicity and age according to the distribution of the Singapore population in 2014. An invitation letter was sent to each resident, and subsequently an interviewer visited the home of the resident to obtain his/her consent to participate in the study. Trained interviewers from a survey research firm conducted the face-to-face interviews with residents who agreed to participate. Residents, who were unable to participate in the interview due to severe physical or mental illness; those living outside of Singapore, institutionalised or hospitalised for the duration of the study; and those who were unable to communicate either in English, Mandarin or Malay were excluded from the study. Further methodological details can be found in an earlier paper. ${ }^{24}$

The overall response rate for the survey was $69.5 \%$ and a total of 6,126 respondents participated in the study. Among these respondents, 4,916 who preferred to take the interview in English were provided with the PMHI (as the instrument was available only in English) and a postage-paid envelope. Respondents were informed by the trained interviewers to complete the PMHI, place it in the sealable envelope and mail it back to the study team. Given the multidimensional nature of the PMHI with 47 items and 6 subscales, and to avoid response bias, participants were given ample time and privacy to complete the self-administered PMHI. The PMHI was completed and returned by 2,337 respondents. Data from a total of 2,270 respondents were included in this analysis with the rest $(n=67)$ excluded due to missing data or pattern answer ${ }^{31}$ (Fig. 1).

\section{Survey interview}

The fully-structured computer-assisted personal interview version of the World Health Organization Composite International Diagnostic Interview version 3.0 (WHO-CIDI 3.0) was the main questionnaire used in this study. ${ }^{32}$ The WHO-CIDI 3.0 gathers diagnostic information on a range of mental disorders. Only select diagnostic modules of the WHO-CIDI 3.0 were administered to the respondents to reduce respondent burden. Socio-demographic information on age, sex, ethnicity, marital status, education level and employment status was obtained from the respondents.

\section{Diagnostic assessment}

The WHO-CIDI 3.0 is designed to generate diagnostic information according to definitions and criteria of the

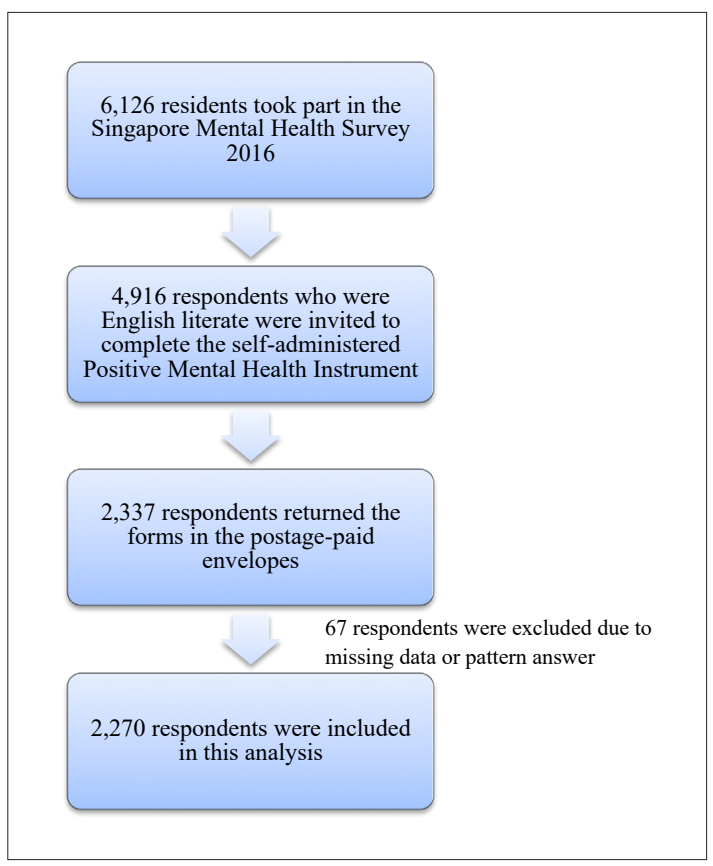

Fig. 1. Flow diagram to describe study procedure.

Diagnostic and Statistical Manual of Mental Disorders, 4th Edition (DSM-IV) and the International Classification of Disease, 10th Revision (ICD-10) Classification of Mental and Behavioral Disorders. ${ }^{33,34}$ Five select disorders diagnosed according to the DSM-IV criteria: alcohol use disorder, generalised anxiety disorder, obsessive-compulsive disorder, MDD and bipolar disorder were assessed in SMHS 2016. Each of the diagnostic modules reported lifetime and 12-month prevalence of the mental disorders. Diagnoses reported here focused on lifetime diagnoses of MDD, and were made using organic exclusions and diagnostic hierarchy rules.

\section{Positive Mental Health Instrument (PMHI)}

The self-administered 47-item PMHI encompasses 6 subscales used to assess PMH: (1) general coping (GC) (9 items), e.g. "When I feel stressed, I do something to get my mind off the situation"; (2) emotional support (ES) (7 items), e.g. "I have people in my life who give me support"; (3) spirituality (7 items), e.g. "I find comfort in my religion or spiritual beliefs"; (4) interpersonal skills (IS) (9 items), e.g. "I make friends easily"; (5) personal growth and autonomy (PGA) (10 items), e.g. "I am focused on what I want to do in life"; and (6) global affect (GA) (5 items). The PMHI was developed and validated among a multi-ethnic adult population in Singapore. ${ }^{25,26}$ For the first 5 subscales, respondents were asked to indicate how much each item described them on a scale from 1 to $6(1$ : Not at all like me to 6: Exactly like me). The GA subscale 
requires respondents to indicate "how often over the past four weeks they felt - calm, happy, peaceful, relaxed and enthusiastic" using a 5-point response scale (1: Never or very rarely to 5 : Very often or always). Domain-specific scores were calculated by summing the scores of the individual items and dividing by the number of items in each domain, likewise, for the total PMH score. Cronbach's alpha $(\alpha)$ for the PMHI was 0.951 in the study sample $(\alpha=0.942$ and $\alpha=0.951$ among those with and without any lifetime mental disorders, respectively). ${ }^{31}$

\section{Statistical analyses}

IBM SPSS Statistics version 23 (IBM Corp, Armonk, US) was utilised to conduct the analyses. All estimates were weighted to adjust for oversampling, non-response weight and post-stratification for age and ethnicity distributions between the study sample and the Singapore resident population in 2014. Characteristics of the overall sample were obtained with descriptive analyses. Multiple logistic regression analyses were performed to look at the sociodemographic correlates of total $\mathrm{PMH}$ and its domains among those with lifetime MDD. Employment status was transformed into 3 dummy coded variables: employed, economically inactive (students, homemakers and retirees/pensioners) and unemployed, with the unemployed variable treated as the reference group. This was to observe how employed persons differed from the unemployed persons. Moderation effect was tested using the SPSS PROCESS module version 3.3 by Hayes. ${ }^{35}$ To pursue the testing for the moderation effect, the following relationships have to be significant: (1) direct effect of predictor (lifetime MDD) on $\mathrm{PMH}$, (2) direct effect of moderator (employment status) on $\mathrm{PMH}$, and (3) direct interactions effect (lifetime MDD x employment status) on PMH. The interaction effect is auto-calculated in SPSS PROCESS, which also generates the proportion of the variance explained by the moderating effect of perceived social support ( $\mathrm{R}^{2}$ increase due to interaction). The effect of the socio-demographic correlates (age, sex, ethnicity, education, marital and employment status) was adjusted in the moderation model.

\section{RESULTS}

\section{Socio-demographic characteristics}

Table 1 displays the demographic distribution of the study population $(n=2,270)$. The mean age of the respondents was 42.1 years. There were slightly more women $(52.1 \%)$ than men $(47.9 \%)$, and majority were Chinese $(77.5 \%)$, married $(55.7 \%)$, university educated $(39.7 \%)$ and employed (74.3\%). The lifetime prevalence of MDD in this sample was $6.6 \%(\mathrm{n}=131)$. Among the
131 individuals with MDD, 10 reported that they were unemployed at the time of the survey.

\section{PMH total and domain scores and socio-demographic correlates}

Individuals with lifetime MDD reported significantly lower PMH total and domain scores compared to those who did not have MDD (Table 2). The results of the socio-demographic correlates of those with lifetime MDD have been tabulated in Table 3. The employed group (versus unemployed) reported significantly higher scores in PMH total $(\beta=1.09, P<0.01)$ and domains GC $(\beta=1.0, P=0.01)$, ES $(\beta=1.68, P<0.001)$, spirituality $(\beta=1.74, P=0.02)$ and GA $(\beta=1.31, P<0.01)$. Similarly, significantly higher scores were observed in PMH total $(\beta=1.24, P<0.01)$ and domains GC $(\beta=1.10, P=0.012)$, ES $(\beta=1.94, P<0.001)$, spirituality $(\beta=1.83, P=0.04)$ and GA $(\beta=1.51, P<0.01)$ in the economically inactive group (vs unemployed). Those with secondary education and those with vocational/Institute of Technical Education (vs university) had significantly lower scores in spirituality $(\beta=-1.38, P=0.01)$ and $\mathrm{GC}(\beta=-0.85, P=0.01)$, respectively. Those of Malay ethnicity (vs Chinese ethnicity) had significantly high scores in the spirituality $(\beta=2.09, P<0.001)$ domain. Females (vs males) were observed to report significantly higher scores for the ES $(\beta=0.75, P<0.001)$ and spirituality $(\beta=0.68, P=0.03)$ domains. A positive linear relationship was observed between age and PMH total $(\beta=0.02, P<0.01), \mathrm{GC}$ $(\beta=0.03, P<0.01)$ and spirituality $(\beta=0.04, P<0.01)$ domains.

\section{Moderation analysis}

Employment status and lifetime MDD were included in the moderation analysis, and these variables accounted for a significant amount of variance in PMH and its domains as shown in Table 4.

The direct effect of lifetime MDD on PMH total $(\beta=-0.329,95 \%$ confidence interval [CI] -0.471 , $-0.188 ; P<0.001)$ and the domains GC $(\beta=-0.482,95 \%$ CI $-0.668,-0.295 ; P<0.001)$, ES $(\beta=-0.382,95 \%$ CI $-0.567,-0.196 ; P<0.001)$, IS ( $\beta=-0.221,95 \%$ CI -0.374 , $-0.069 ; P=0.01)$, PGA $(\beta=-0.387,95 \%$ CI $-0.550,-0.224$; $P<0.001)$ and GA $(\beta=-0.452,95 \%$ CI $-0.630,-0.275$; $P<0.001)$ was observed to be significant. The direct effect of being economically inactive was noted to be significant on PMH total $(\beta=0.076,95 \%$ CI $0.009,0.143$; $P=0.03)$ and the domains spirituality $(\beta=0.281,95 \%$ CI $0.131,0.431 ; P<0.001)$, IS $(\beta=-0.074,95 \%$ CI $0.003,0.146 ; P=0.04)$ and $\mathrm{GA}(\beta=0.088,95 \%$ CI $-0.630,-0.275 ; P=0.04)$. The interaction term 
Table 1. Socio-demographic and mental health characteristics of participants who completed the Positive Mental Health Instrument

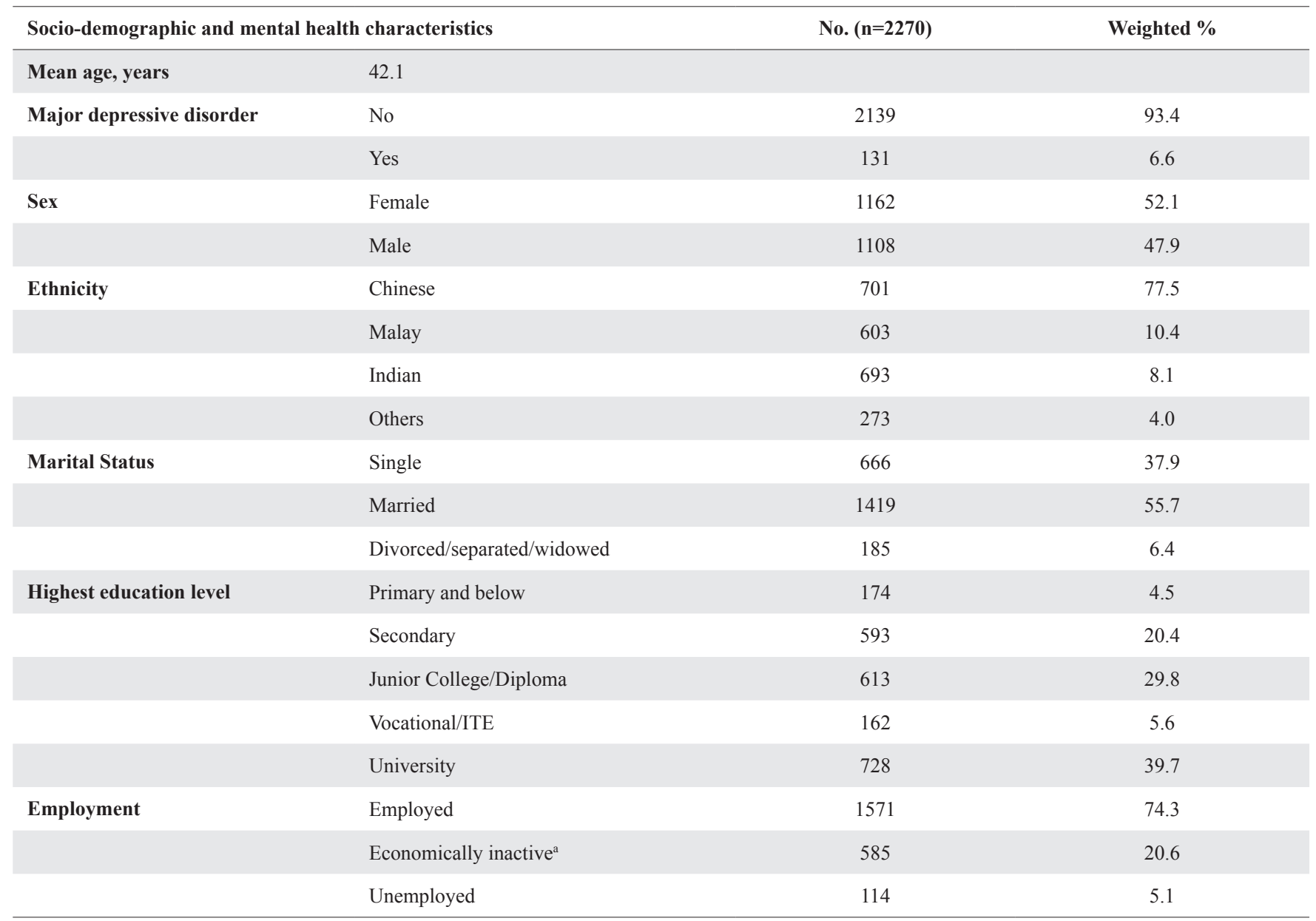

ITE: Institute of Technical Education

${ }^{a}$ Includes students, homemakers and retirees/pensioners

between unemployed and lifetime MDD accounted for a significant proportion of the variance in $\mathrm{PMH}$ total $(\beta=-0.741,95 \%$ CI $-1.209,-0.274) ; P<0.01)$ and specific domains; ES $(\beta=-0.926,95 \%$ CI $-1.540,-0.312 ; P<0.01)$, spirituality $(\beta=-1.170,95 \%$ CI $-2.222,-0.119 ; P=0.03)$; PGA $(\beta=-0.668,95 \%$ CI $-1.207,-0.128 ; P=0.02)$ and GA $(\beta=-1.060,95 \%$ CI $-1.649-0.472 ; P<0.001)$. Although the direct effect of those who were economically inactive on PMH was significant (i.e. those who were economically inactive had a better PMH), the interaction between this group and those with lifetime MDD was not significant. Examination of the interaction plots (Fig. 2) showed that the effect of lifetime MDD on PMH total was minimal among those who were employed (mean difference $=0.33$ ) compared to those who were unemployed (mean difference=1.06). The same was observed in the PMH domains, GC (mean difference $=0.67$ ). Respondents with lifetime MDD who were unemployed had poor PMH compared to those who were employed.

\section{DISCUSSION}

The intent of this paper was firstly to present the differences in PMH levels among those with and without lifetime MDD. Those with lifetime MDD had lower mean PMH scores across all domains and total scores indicating that the presence of MDD is associated with lower mental well-being. Growing evidence suggests high levels of PMH protect individuals from mental illness. Keyes et al. ${ }^{36}$ conducted a longitudinal study with mentally healthy participants, and showed that those with high levels of PMH over a 10-year period had a decreased risk of developing a mental illness and that participants whose PMH declined had significantly increased odds of developing a mental illness. This points to the existence of a bidirectional relationship between PMH and mental disorders, which is supported by the findings of other studies. Grant et al..$^{37}$ found that reduced levels of PMH predicted risk of higher depressive symptoms within a year; a similar finding was reported by Lamers et al. ${ }^{38}$ Mental health protection and 
promotion is crucial to reduce the burden of mental illness, and it can be attained by building and maintaining high levels of PMH.

Socio-demographic correlates, notably, employment status (PMH total, GC, ES, spirituality and GA), ethnicity (Malay: spirituality) and sex (female: ES and spirituality) were more commonly associated with higher PMH total and domain scores in those with MDD. These findings are consistent with the findings of other studies, which have shown that females tend to report higher positive well-being and higher scores on psychological well-being scales compared to their male counterparts. ${ }^{39,40}$ A Singapore study among outpatients with schizophrenia ${ }^{41}$ also revealed that females had significantly higher total $\mathrm{PMH}$ and domain specific scores.

In the current dataset (SMHS 2016), among individuals with lifetime MDD, Malays reported significantly higher scores in the spirituality domain. Ethnic differences in mental health have been well documented. ${ }^{42-44}$ Singapore has long been a multireligious society in which religion and spirituality seem to have a close relationship. ${ }^{45}$ Religious identity in Singapore is demonstrated to be the strongest among the Muslims, an ethnic group that is largely made up of Malays followed by Indians. ${ }^{46}$ It has been reported that Malays tend to score high on religiosity and spirituality based on the frequency of prayers and attendance at religious services. ${ }^{47-49}$ Studies have also continued to show the positive effect of religiosity and spirituality on physical and mental health. ${ }^{49-51}$ Religious or spiritual coping is seen as comforting during times of distress as individuals tend to seek religions or spirituality as a means of strength in difficult times. Deci and Ryan ${ }^{10}$ discussed that self-determination theory is closely connected to the issue of religiosity and mental health. The theory is based on the idea that the process of internalising values such as adopting beliefs or practices can have a significant impact on psychological wellbeing. ${ }^{52}$

Our study revealed that compared to the unemployed, those who were economically inactive (students, homemakers and retirees/pensioners) and employed had a higher PMH. Mental and economic well-being are inherently related. Mental health is known to be a crucial factor of production - people with poor mental health have lower levels of economic activity, lower earnings, less stable employment and lower financial security ${ }^{15}$ Poor mental health creates lower levels of economic activity, lower wages and less stable employment. On the other hand, mental health can be undermined by employment difficulties. Those who struggle to find meaningful work or lose their source of income experience poorer

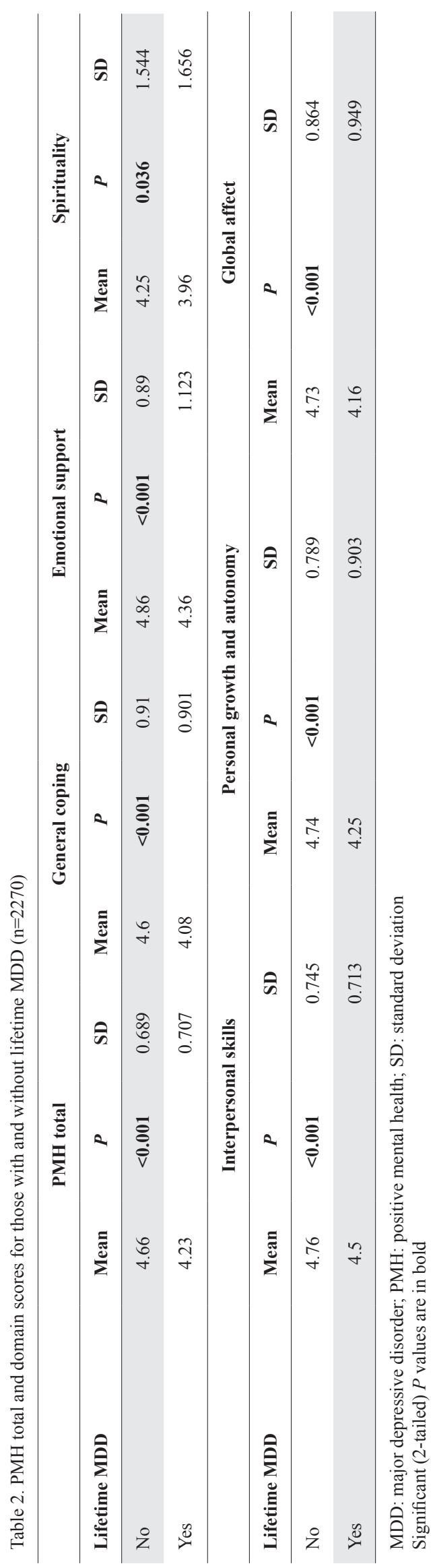




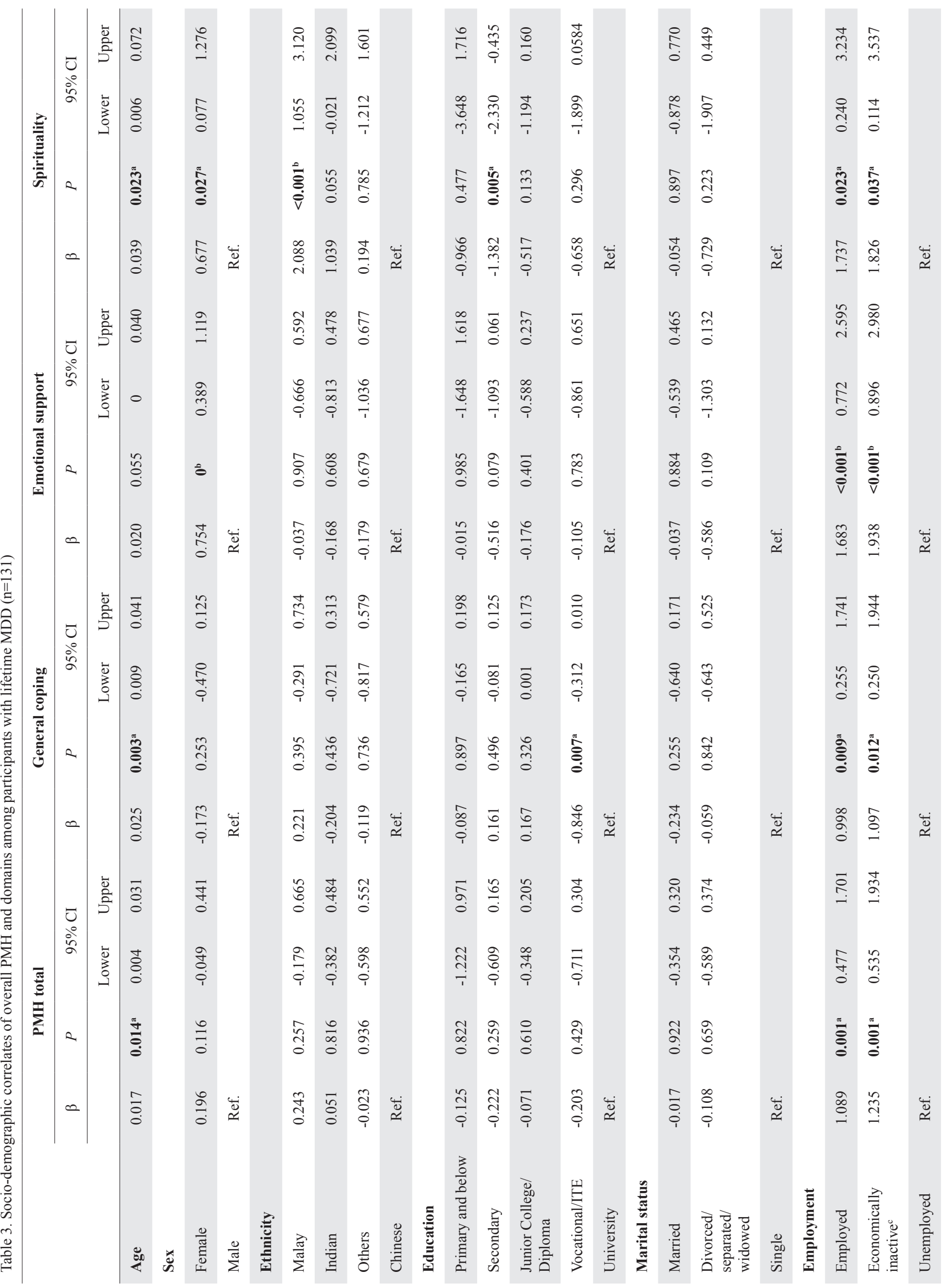




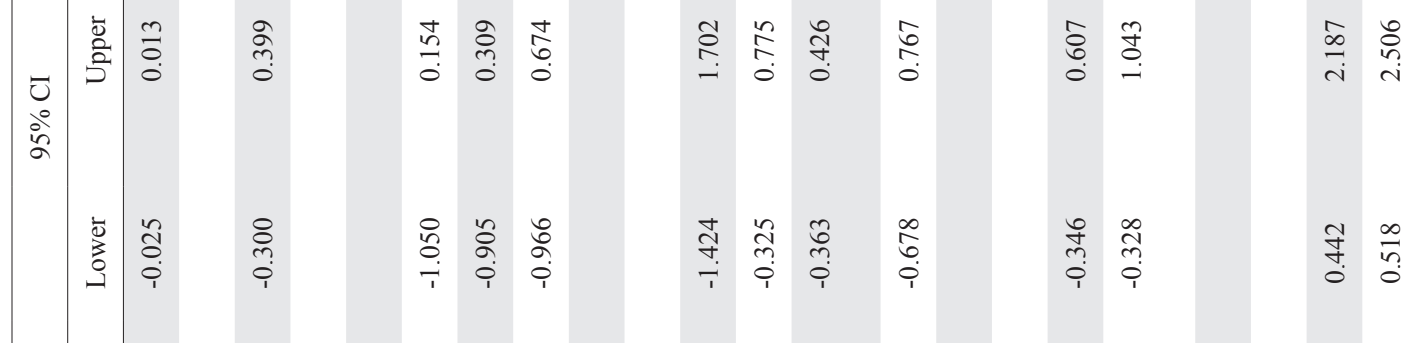

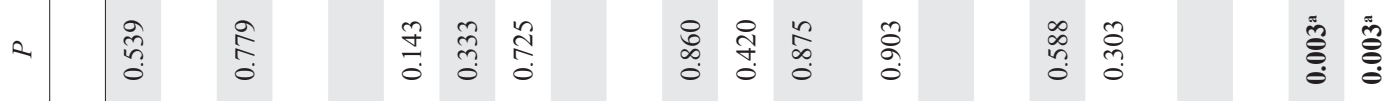

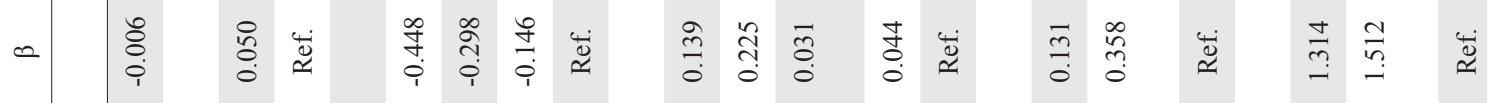

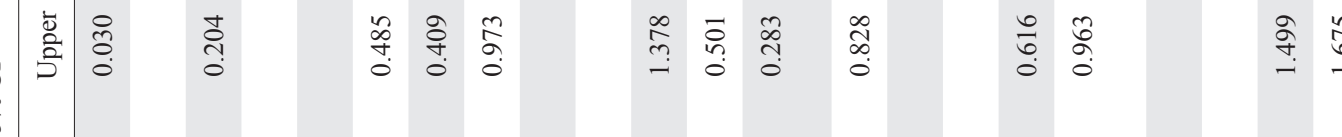

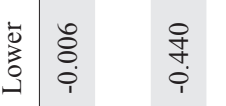

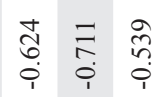

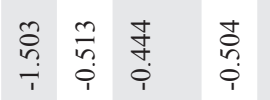

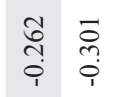

$\stackrel{\substack{n \\:}}{\stackrel{n}{i}}$

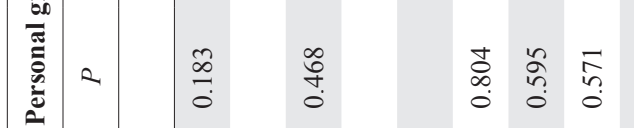

స్.

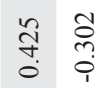

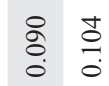

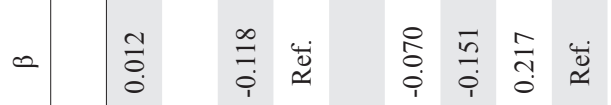

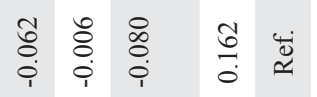

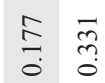

๕ே.

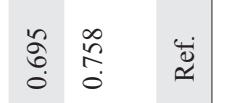

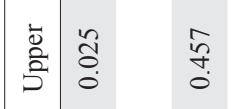

तิ $\begin{array}{ccc}n & \overline{0} \\ 0 & n & 0 \\ 0\end{array}$

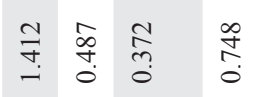

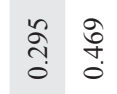

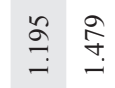

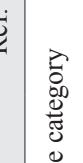

ปั่<smiles>C1CC1</smiles>

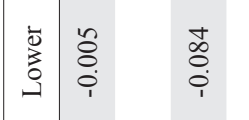

$\begin{array}{lll}1 & 8 & 0 \\ 0 & 0 \\ 0 & 1 & 0 \\ 0 & 0 & 0\end{array}$

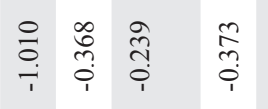

辛

in

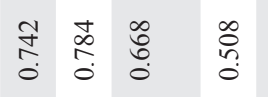

$\begin{array}{ll}0 & 0 \\ 0 & 0 \\ 0 & 0 \\ 0 & 0 \\ 0 & 0\end{array}$

$\stackrel{m}{\stackrel{m}{0}}$

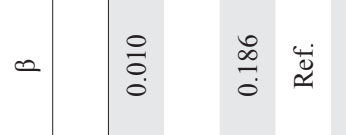

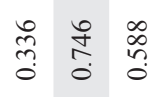

힝

م.

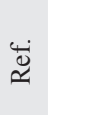

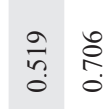

$\frac{3}{0}$

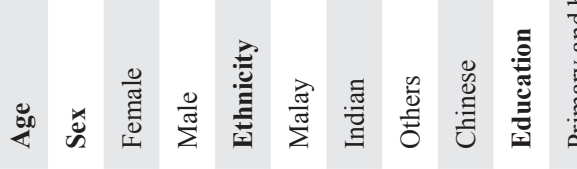

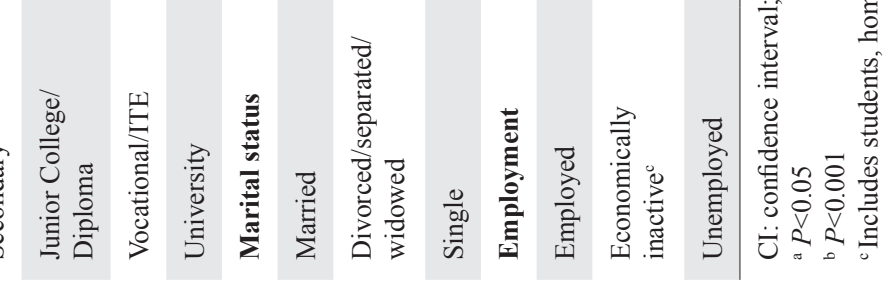




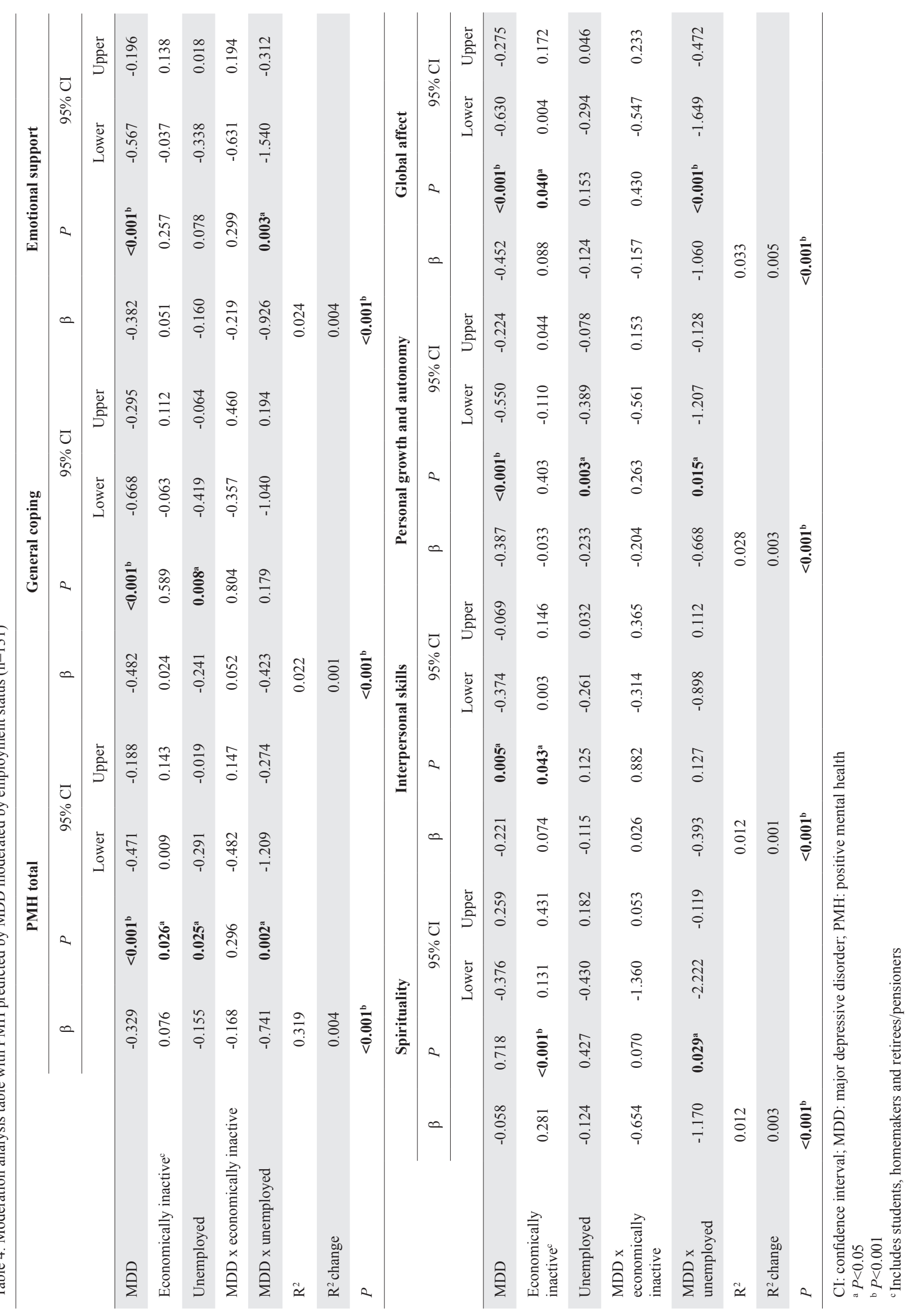



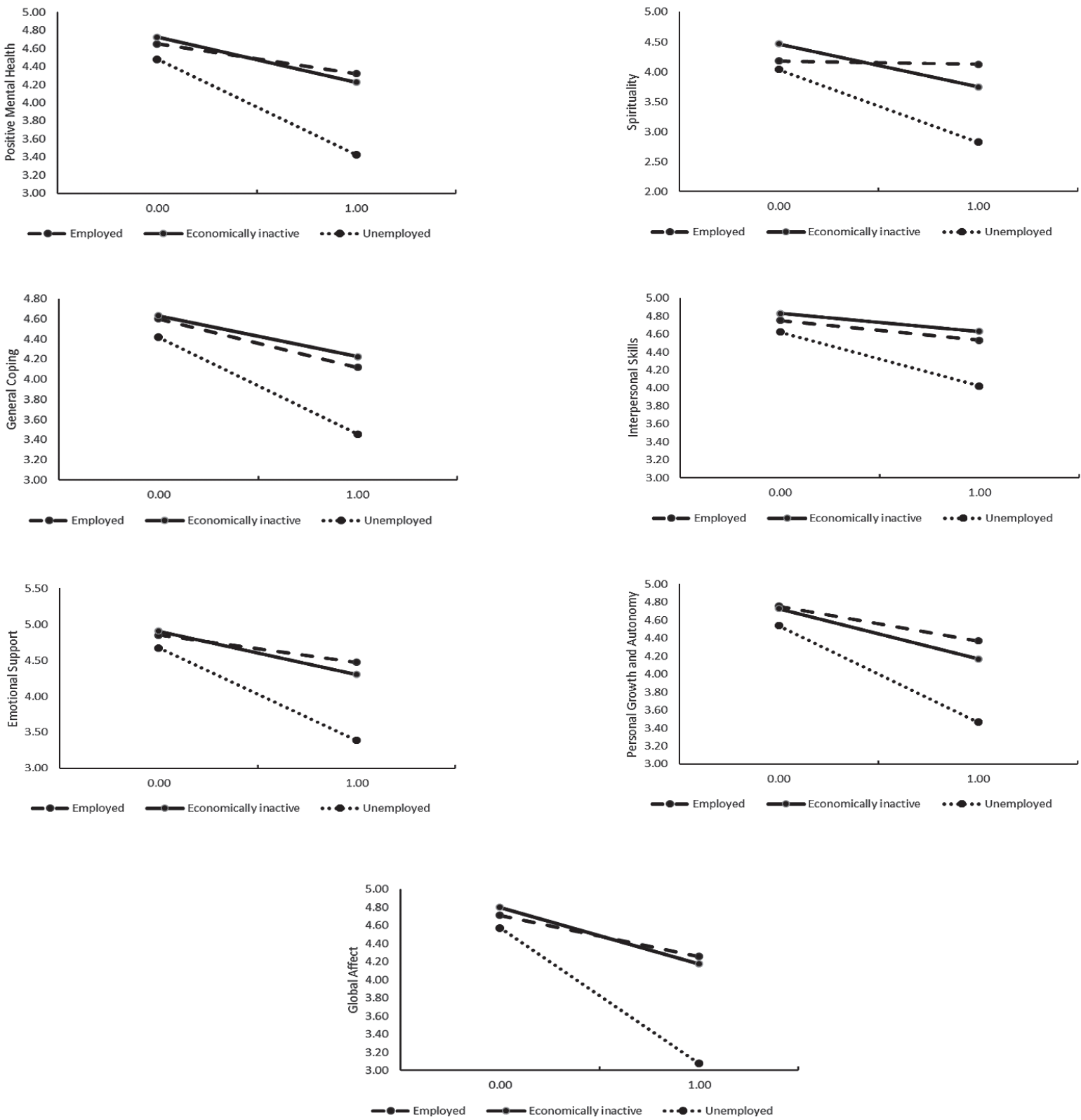

Fig. 2. Significant interaction of employment status and lifetime MDD on PMH. MDD: major depressive disorder; PMH: positive mental health

mental well-being. ${ }^{53}$ Given the extensive literature on the bilateral relationship of employment status and mental well-being, this study intended to examine the moderating effects that employment status has on the relationship between lifetime MDD and PMH. ${ }^{18,19}$ It was clearly depicted that presence of lifetime MDD with the concurrence of unemployment had a greater negative impact on PMH. Those who were unemployed had poor PMH. Exposure to unemployment brings about an increased vulnerability, and can affect the psychological well-being of the individuals exposed to joblessness, including their outlook on life in general, their emotional status, cognitive efficiency and attitude towards work. Factors such as these may influence the possibility of them re-joining the workforce. ${ }^{54}$ Extant literature has discussed that depression is associated with cognitive impairment, which in turn, may result in poor job performance, causing unemployment. ${ }^{55}$ However, conclusions about causality cannot be drawn due to the cross-sectional nature of this study. Eisenberg 
and Lazarsfeld ${ }^{56}$ used a descriptive study to list the unpleasant and emotionally negative consequences of unemployment; since psychological well-being is a multidimensional concept, the impact of unemployment on mental health can manifest as depression, anxiety, low self-esteem and strained personal relations. The Korea Welfare Panel Study revealed that a negative change in employment status and remaining in unstable employment or unemployment are associated with having depression. ${ }^{57}$ Paul and Moser $^{20}$ reported that a person who is unemployed does not have access to the 5 latent functions of employment: structured time, social contact, collective purpose, status and activity that were first identified by Jahoda. ${ }^{58}$ Jahoda pointed out that unemployment is psychologically damaging because the individual is deprived of these latent functions. He asserted that even unsatisfactory employment is more desirable than the absence of work. Job loss also affects heath, as stress is caused by the expectation of termination, the process of termination, unemployment and the job search. ${ }^{59}$ It will be essential to monitor the health outcomes of those unemployed and having MDD. The results further reiterate the necessity to encourage workplace mental health, including screening for psychological distress and initiation of early antidepressant treatment, which that can in turn provide support for continual employment. ${ }^{60}$

Those who were economically inactive (students, homemakers and retirees/pensioners) reported a significantly higher PMH compared to the unemployed. Interestingly, the interaction between the economically inactive and those with lifetime MDD was negative, indicating that this group (people who had lifetime MDD and were economically inactive) tended to have poorer $\mathrm{PMH}$. However, the interaction was seen as insignificant, which could be due to the small sample size for this group, and therefore not large enough for a notable effect. Poorer PMH for the retirees/pensioners, however, could be explained by poor self-reported health and functional status that are observed among the elderly with depressive symptoms associated with specific chronic illnesses. ${ }^{61}$

There are several limitations of the current study. The cross-sectional survey design does not permit any causal inferences. Only English-speaking adults were included in the current study. This study relied on self-report for the diagnosis of mental illness, which could lead to some bias in the findings. There is a likelihood of participants over-reporting PMH due to social desirability bias. To reduce this bias and allow for adequate time to complete the questionnaire, participants were required to place the completed questionnaire in a postage-paid, sealable envelope and mail it back to the study team at a later date. Not all respondents $(n=2,579)$ who were invited to complete the self-administered PMHI returned the forms, and this can contribute to limiting the representation of the sample to a certain degree. Participants could be unemployed on their own accord or due to compulsory redundancies, and these could contribute to different implications for mental health-however, reasons for unemployment were not collected. Notwithstanding these limitations, the strength of the study lies in the use of validated PMHI in Singapore, which encompasses important domains that were similarly identified in other models of PMH. ${ }^{62,63}$ The study is also strengthened with data collected from a representative sample, increasing the generalisability of the findings to the Singapore population.

\section{CONCLUSION}

In order to care for a person's mental well-being in a holistic manner, clinicians and allied health professionals should systematically support the employment needs of those who report lifetime MDD by adopting a clientcentered approach, and work towards the vocational goals of their clients while facilitating the sustainability of employment. On a societal level we will have to ensure that earlier access to specialist services is provided to such individuals, look into addressing both employment and mental health needs of the individuals, and reducing the barriers to employment for those with mental health issues, so that the PMH of the person can be improved. The comprehensive effects of employment status-including differences in types of employment and reasons for unemployment - on health outcomes and self-rated PMH should be investigated in further studies. Such research will to introduce more integration between current healthcare services or propose innovative applications of current evidencebased models.

\section{REFERENCES}

1. Kessler RC, Aguilar-Gaxiola S, Alonso J, et al. The global burden of mental disorders: an update from the WHO World Mental Health (WMH) surveys. Epidemiol Psichiatr Soc 2009;18:23-33.

2. Baxter AJ, Scott KM, Vos T, et al. Global prevalence of anxiety disorders: a systematic review and meta-regression. Psychol Med 2013;43:897-910

3. Steel Z, Marnane C, Iranpour C, et al. The global prevalence of common mental disorders: a systematic review and meta-analysis 1980-2013. Int J Epidemiol 2014;43:476-93.

4. Ishikawa H, Tachimori H, Takeshima T, et al. Prevalence, treatment, and the correlates of common mental disorders in the mid 2010's in Japan: The results of the world mental health Japan 2nd survey. J Affect Disord 2018;241:554-62. 
5. World Health Organization. Mental health: strengthening our response. Fact sheet N.2202010;1-4.

6. Keyes CLM. Mental illness and/or mental health? Investigating axioms of the complete state model of health. J Consult Clin Psychol 2005;73:539-48

7. Suldo SM, Shaffer EJ. Looking Beyond Psychopathology: The Dual-Factor Model of Mental Health in Youth. School Psych Rev 2008;37:52-68.

8. Keyes CLM, Shmotkin D, Ryff CD. Optimizing well-being: The empirical encounter of two traditions. J Pers Soc Psychol 2002;82:1007-22.

9. Huppert FA. Positive mental health in individuals and populations. In: The Science of Well-Being. Oxford University Press; 2012

10. Deci EL, Ryan RM, Deci EL, et al. Conceptualizations of Intrinsic Motivation and Self-Determination. In: Intrinsic Motivation and Self-Determination in Human Behavior. Boston: Springer; 1985

11. Bošković G, Jengić VS. Mental health as eudaimonic well-being? Psychiatr Danub 2008;20:452-5.

12. Iasiello M, van Agteren J, Keyes CLM, et al. Positive mental health as a predictor of recovery from mental illness. J Affect Disord $2019 \cdot 251: 227-30$

13. Dorji N, Dunne M, Gurung M. Socio-demographic correlates of psychological wellbeing among older adults in Bhutan. Environ Soc Psychol 2019;4:1-8.

14. Caron J, Liu A. Factors associated with psychological distress in the Canadian population: A comparison of low-income and non low-income sub-groups. Community Ment Health J 2011;47:318-30.

15. Layard R. Mental health: the new frontier for labour economics. IZA J Labor Policy 2013;2:1-16.

16. OECD. Mental Health and Work: Denmark. Paris: OECD Publishing; 2013.

17. International Labour Organization. Employment Security. 2016. Available at: https://www.ilo.org/global/lang--en/index.htm. Accessed on 8 October 2021.

18. Inanc H. Unemployment, Temporary Work, and Subjective Well-Being: The Gendered Effect of Spousal Labor Market Insecurity. Am Sociol Rev 2018;83:536-66.

19. Rizvi SJ, Cyriac A, Grima E, et al. Depression and employment status in primary and tertiary care settings. Can J Psychiatry 2015;60:14-22.

20. Paul KI, Moser K. Unemployment impairs mental health: Metaanalyses. J Vocat Behav 2009;74:264-82.

21. Singapore Department of Statistics. Singapore in Figures 2018. Available at: https://www.singstat.gov.sg/-/media/files/publications/ reference/sif2018.pdf. Accessed on 8 October 2021.

22. Singapore Ministry of Manpower. Labour Market Statistics and Publications. Summary Table: Unemployment. Available at: https://stats. mom.gov.sg/Pages/Unemployment-Summary-Table.aspx. Accessed on 8 October 2021.

23. Chong SA, Vaingankar J, Abdin E, et al. The prevalence and impact of major depressive disorder among Chinese, Malays and Indians in an Asian multi-racial population. J Affect Disord 2012;138:128-36.

24. Subramaniam M, Abdin E, Vaingankar JA, et al. Tracking the mental health of a nation: Prevalence and correlates of mental disorders in the second Singapore mental health study. Epidemiol Psychiatr Sci 2019;29:e29.

25. Vaingankar JA, Subramaniam M, Chong SA, et al. The positive mental health instrument: Development and validation of a culturally relevant scale in a multi-ethnic asian population. Health Qual Life Outcomes 2011;9:92.
26. Vaingankar JA, Subramaniam M, Abdin E, et al. Socio-demographic Correlates of Positive Mental Health and Differences by Depression and Anxiety in an Asian Community Sample. Ann Acad Med Singap 2013;42:514-23.

27. Vaingankar JA, Subramaniam M, Tan LWL, et al. Psychometric properties and population norms of the positive mental health instrument in a representative multi-ethnic Asian population. BMC Med Res Methodol 2018;18.

28. Sambasivam R, Vaingankar JA, Chong SA, et al. Positive mental health in outpatients: Comparison within diagnostic groups. BMC Psychiatry 2016;16.

29. Seow LSE, Vaingankar JA, Abdin E, et al. Positive mental health in outpatients with affective disorders: Associations with life satisfaction and general functioning. J Affect Disord 2016; 190:499-507.

30. Ho RCM, Mak KK, Chua ANC, et al. The effect of severity of depressive disorder on economic burden in a university hospital in Singapore. Expert Rev Pharmacoecon Outcomes Res 2013; 13:549-59.

31. Vaingankar JA, Chong SA, Abdin E, et al. Understanding the relationships between mental disorders, self-reported health outcomes and positive mental health: Findings from a national survey. Health Qual Life Outcomes 2020;18.

32. Kessler RC, Ustün TB. The World Mental Health (WMH) Survey Initiative Version of the World Health Organization (WHO) Composite International Diagnostic Interview (CIDI). Int J Methods Psychiatr Res 2004;13:93-121.

33. American Psychiatric Association. Diagnostic and statistical manual of mental disorders, 4th Edition (DSM-IV). Washington: American Psychiatric Association; 1994.

34. World Health Organization. The ICD-10 classification of mental and behavioural disorders. Geneva: World Health Organization; 1993.

35. Hayes AF. Introduction to Mediation, Moderation, and Conditional Process Analysis: A Regression-Based Approach. 2nd Ed. New York: The Guilford Press; 2017.

36. Keyes CLM, Dhingra SS, Simoes EJ. Change in level of positive mental health as a predictor of future risk of mental Illness. Am J Public Health 2010;100:2366-71.

37. Grant F, Guille C, Sen S. Well-Being and the Risk of Depression under Stress. PLoS One 2013;8:e67395.

38. Lamers SMA, Westerhof GJ, Glas CAW, et al. The bidirectional relation between positive mental health and psychopathology in a longitudinal representative panel study. J Posit Psychol 2015; 10:553-60.

39. Wood W, Rhodes N, Whelan M. Sex Differences in Positive Well-Being: A Consideration of Emotional Style and Marital Status. Psychol Bull 1989;106:249-64.

40. Ryff CD, Keyes CLM. The Structure of Psychological Well-Being Revisited. J Pers Soc Psychol 1995;69:719-27.

41. Jeyagurunathan A, Vaingankar JA, Abdin E, et al. Gender differences in positive mental health among individuals with schizophrenia. Compr Psychiatry 2017;74:88-95.

42. U.S. Departmemt of Health and Human Services. Mental health: culture, race, and ethnicity - a supplement to mental health: a report of the Surgeon General. Rockville: U.S. Department of Health and Human Services, Substance Abuse and Mental Health Services Administration, Center for Mental Health Services; 2001.

43. Takeuchi DT, Williams DR. Race, ethnicity and mental health: Introduction to the special issue. J Health Soc Behav 2003; 44:233-6. 
44. Erdem Ö, Burdorf A, Van Lenthe FJ. Ethnic inequalities in psychological distress among urban residents in the Netherlands: A moderating role of neighborhood ethnic diversity? Heal Place 2017;46:175-82.

45. Lai AE (Ed.). Religious diversity in Singapore. Singapore: Institute of Southeast Asian Studies / Institute of Policy Studies; 2008.

46. Mathews M, Mohammad Khamsya BK, Kay Key T, et al. Religiosity and the management of religious harmony: Responses from the IPS survey on race, religion and language. IPS Working Papers No. $21 ; 2014$

47. Noor Laily DAB, Tan BA, Tey NP, et al. Ethnicity and Fertility in Malaysia. Singapore: Institute of Southeast Asian Studies; 1985.

48. Rashid Moten A, Wok S. Religiosity of Malays Living in Malaysian Rural Areas: An Analytical Survey. IJIT 2019;15:1-16

49. Francis B, Gill JS, Yit Han N, et al. Religious Coping, Religiosity, Depression and Anxiety among Medical Students in a Multi-Religious Setting. Int J Environ Res Public Health 2019;16:259.

50. Weaver AJ, Koenig HG. Religion, spirituality, and their relevance to medicine: An update. Am Fam Physician 2006;73:1336-7.

51. Yaacob SN, Aun TS, Rahim SMBA, et al. Religiosity and internal developmental assets amongst Malay adolescents in Malaysia. Asian Soc Sci 2015;11:181-8.

52. Ryan RM, Rigby S, King K. Two Types of Religious Internalization and Their Relations to Religious Orientations and Mental Health. J Pers Soc Psychol 1993;65:586-96.
53. Nica E, Manole C, Briscariu R. The detrimental consequences of perceived job insecurity on health and psychological well-being. Hum Resour Manag 2016;4:175-81.

54. Darity W, Goldsmith AH. Social Psychology, Unemployment and Macroeconomics. J Econ Perspect 1996;10:121-40.

55. Husain SF, Yu R, Tang TB, et al. Validating a functional near-infrared spectroscopy diagnostic paradigm for Major Depressive Disorder. Sci Rep 2020;10:1-9.

56. Eisenberg P, Lazarsfeld PF. The psychological effects of unemployment. Psychol Bull 1938;35:358-90.

57. Yoo KB, Park EC, Jang SY, et al. Association between employment status change and depression in Korean adults. BMJ Open 2016;6:e08570

58. Jahoda M. Employment and unemployment: A social-psychological analysis. New York: Cambridge University Press; 1982.

59. Mandal B, Ayyagari P, Gallo WT. Job loss and depression: The role of subjective expectations. Soc Sci Med 2011;72:576-83.

60. Lee Y, Rosenblat JD, Lee JG, et al. Efficacy of antidepressants on measures of workplace functioning in major depressive disorder: A systematic review. J Affect Disord 2018;227:406-15.

61. Niti M, Ng T-P, Kua EH, et al. Depression and chronic medical illnesses in Asian older adults: the role of subjective health and functional status. Int J Geriatr Psychiatry 2007;22:1087-94.

62. Jahoda M. Current concepts of positive mental health. New York: Basic Books; 1958.

63. Ishizuka Y. 794 - Treating personality. Eur Psychiatry 2013;28(S1):1. 